\title{
Specialized technology suppliers, international spillovers and investment: evidence from the chemical industry
}

\author{
Ashish Arora ${ }^{\mathrm{a}, *}$, Andrea Fosfuri ${ }^{\mathrm{b}, \mathrm{c}}$, Alfonso Gambardella ${ }^{\mathrm{d}}$ \\ ${ }^{\mathrm{a}}$ Heinz School of Public Policy and Management, Carnegie Mellon University, 5000 Forbes Avenue, \\ Pittsburgh, PA 15213-3890, USA \\ ${ }^{\mathrm{b}}$ Universidad Carlos III de Madrid, Calle Madrid, 126, 28903 Getafe Madrid, Spain \\ ${ }^{\mathrm{c}}$ CEPR, 90-98 Goswell Road, London EC1V 7RR, UK \\ d Sant'Anna School of Advanced Studies, University of Pisa, Via Carducci, 40, 56127 Pisa, Italy
}

\begin{abstract}
In this paper we study how the development of specialized upstream technology suppliers in leading countries improves technology access and lowers investment costs for downstream firms in follower countries. We test this idea using a novel database covering all investments in chemical plants in less developed countries (LDCs) during the 1980s. We find that investments in chemical plants in the LDCs are greater, the greater is the number of technology suppliers that operate in the first world. A major contribution of this paper is to identify an important but understudied mechanism through which technology is made available. (C) 2001 Elsevier Science B.V. All rights reserved.
\end{abstract}

JEL classification: $\mathrm{O} 33 ; \mathrm{D} 2 ; \mathrm{O} 12 ; \mathrm{L} 65$

Keywords: Market for technology; Specialization; Technology supply; Investment; Chemical industry

\footnotetext{
* Corresponding author. Tel.: +1-412-268-2191; fax: +1-412-268-5161.

E-mail addresses: ashish@andrew.cmu.edu (A. Arora), fosfuri@emp.uc3m.es (A. Fosfuri), agambardella@info-net.it (A. Gambardella).
} 


\section{Introduction}

That specialization and division of labor among firms promote economic welfare is almost an article of faith for economists. Smith's (1776) legacy, passed through Stigler (1951), is that when the optimal scale of production of an input is larger than the optimal size of the user firms, a specialized supplier can produce the input more efficiently because it can spread the fixed cost over a larger volume of output. Hence, division of labor is more extensive in larger markets. In turn, a more efficient production of the input induces the downstream industry to grow more rapidly (Young, 1929).

But while the literature has typically focused on the vertical division of labor within an industry, this paper points out that an important and almost unexplored part of the story lies in the benefits that a division of labor in one market can generate for other markets. Specifically, we focus on how division of labor in one country has beneficial effects for other countries. We argue that when division of labor in a country gives rise to upstream technology suppliers, other countries can benefit as well. Thus, if technology suppliers develop in one country first, then, once the technology is developed, these technology suppliers can sell it to other countries at a small incremental cost (especially if compared with the cost of developing the technology in the first place). In this way, technology developed in leading countries can "spillover" to follower countries.

To examine this issue we study investment in chemical plants in less developed countries during the $1980 \mathrm{~s}$. The chemical industry provides an ideal test-bed. Beginning in the 1930s and continuing into the 1960s, the modern chemical industry in the developed countries (henceforth 'first world') grew rapidly. This stimulated the growth of firms that specialized in the design and engineering of the chemical processes, the so-called 'specialized engineering firms' (SEFs), which are similar to the software engineering and computer consultancy firms that are more visible in the American economy today. SEFs have been important reservoirs of expertise in chemical technologies, which they provide in the form of engineering services to chemical firms. In some cases, SEFs have also developed radical process innovations but for the most part, they supply improved versions of existing technologies packaged with engineering and design services. Other SEFs offered construction services in addition to engineering know-how. In the 1970s, and especially in the 1980s, as a modern chemical industry emerged in the developing countries, it benefited from the presence of these technology suppliers. Simply put, the growth of the chemical industry in the first world created an upstream sector, which later spurred the growth of the chemical industry in the developing countries. ${ }^{1}$

As a guide to our empirical results, we develop a simple model. The model assumes that a larger number of technology suppliers increase the net surplus to buyers from investing in a chemical plant. This is a natural assumption since buyers should benefit from being able to choose from a larger pool of suppliers, and is consistent with a large set of economic explanations that variously emphasize reduced search costs, reduced

\footnotetext{
${ }^{1}$ The story of SEFs and their role in the growth of the chemical industry is told in greater detail in Arora and Gambardella (1998). See also Freeman (1968).
} 
bargaining power of sellers, and a better 'match' between the needs of buyers and the technology. The main result of the model is that if the existing SEFs in the first world are also potential suppliers of technology to developing countries, then the larger the number of first world SEFs in a given market for chemical process technology, the greater is the investment in that market in the developing countries.

The model also predicts that the larger is the number of first world SEFs, the greater is the number of plants in developing countries where engineering services are 'bought' from SEFs, and the smaller the number of plants whose engineering services are 'made' in-house by the chemical firms. Moreover, the impact of an increase in the supply of SEFs is more pronounced for companies that have higher cost of 'making' the technology in-house. This suggests that SEFs are more beneficial for local third world companies than for the multinational enterprises that may also invest in these markets. We test these propositions using data on chemical plant investments in 136 leading chemical technologies and 38 developing countries. These are drawn from a novel and comprehensive data set of more than 20000 chemical plants announced and constructed during the 1980s worldwide.

Section 2 provides the conceptual underpinnings of our approach and links it to the literature on technology, spillovers and growth. Section 3 presents our model. Section 4 discusses the empirical specification and presents our empirical results. Section 5 summarizes our findings and concludes the paper. Appendix A describes our data set.

\section{Markets for technology, international spillovers and the transmission of growth}

This paper is related to several strands in the literature. Our emphasis on the lower cost of using technologies compared with the cost of developing them is similar in spirit to the literature on endogenous growth (e.g., Romer, 1990, 1996). Following Griliches (1979) and Jaffe (1986), there is a well-established literature on technology spillovers, and Coe and Helpman (1995) provide evidence of international technological spillovers (see also Eaton and Kortum, 1996).

Unlike the empirical literature on spillovers, we do not examine the effects of spillovers on total factor productivity but on the flow of investments, because we do not have measures of the total factor productivity at this disaggregate level. However, our paper moves beyond the simple observation that technological spillovers exist, and identifies a mechanism through which they take place-namely, the intermediation of an upstream sector that sells technology inputs through a full-fledged market for technology. ${ }^{2}$ Both real and pecuniary effects may be involved here: SEFs may imply lower technology transfer costs for developing countries, and competition among them may lower the price as well, a purely pecuniary effect. Rich as our data are, we cannot empirically distinguish between the two mechanisms. Thus, although our formalism focuses on the pecuniary externality, real externalities are likely to be involved as well.

\footnotetext{
${ }^{2}$ In other words, some of what appear to be "spillovers" may in fact be market mediated knowledge flows. In a recent paper, Zucker et al. (1998) find that in biotechnology market mechanisms involving individual scientists may account for what appeared to be knowledge spillovers from universities to local firms.
} 
The nature of the mechanism we study is similar to the one highlighted by the recent literature on 'general-purpose technologies' (Bresnahan and Trajtenberg, 1995; Helpman and Trajtenberg, 1996). Such technologies have high fixed costs, but they can be applied repeatedly at low incremental cost. This leads to spillovers across industries in which the growth of one user sector benefits other user sectors through the intermediation of the general-purpose technology industry. Our paper shows that this argument can be extended to the transmission of growth across countries, and it provides empirical evidence of these mechanisms.

It is natural to ask at this point whether our story is not simply a story about international trade. It is, but with one difference. While the standard Heckscher-Ohlin trade model locates comparative advantage in natural resources or factor endowments, we locate it in the fact that chemical engineering services are based on cumulative learning and experience, and that the (fixed) costs of acquiring this expertise are already sunk when the developing country markets arise. Put differently, the first world has a comparative advantage in engineering services because first-world engineering firms were founded more than 50 (and in some cases, more than a 100) years ago in response to the growth of the oil and chemical sectors in their own countries. ${ }^{3}$

By stressing the historical sequence in the rise of new markets, our perspective also differs somewhat from Rivera-Batiz and Romer (1991), who argue that international economic integration increases growth because, with integration, the fixed cost of producing 'ideas' can be spread over a larger market. In our model, integration is beneficial to the follower countries even though the number of SEFs in the first world does not increase when the first world and developing country markets are integrated. Although analytically convenient, our primary reason for assuming that SEFs do not develop in response to growth in developing countries is that it is more faithful to history. Most SEFs arose to serve the first world market, not the developing country markets that did not as yet exist.

Finally, our paper is related to the literature on the product life cycle (e.g., Vernon, 1979), whereby as technologies or products mature, production is transferred from the first world to developing countries. This literature has focused on one mechanism through which this transfer occurs-multinational enterprises (MNEs). This focus has often been justified by the assumption that while downstream products are tradable, upstream inputs are not (e.g., Nadiri, 1993; Rodriguez-Clare, 1996). In fact, in the chemical industry as in many other high-tech industries, a key upstream input-intangible knowledge and expertise - is easier to move across locations, while the final products (chemicals such as ammonia and ethylene) are costly to transport. MNEs are undoubtedly an important vehicle for technology transfer and for the growth of the host countries. However, when technologies are based on systematic body of knowledge like chemical engineering, MNEs are not the only, or even the most efficient, way of transferring technology. Instead, as in the chemical industry, specialized technology

\footnotetext{
${ }^{3}$ Incidentally, this also implies that at the time, the first world market size was much larger than that of the third world.
} 
suppliers competing amongst themselves can be the predominant means of technology transfer.

\section{The theoretical framework}

\subsection{Description of the model}

Fig. 1 summarizes the two effects that we highlight in our model.

First, the growth of the first world market for a given chemical process encourages the rise of engineering firms specialized in the design of chemical plants for that process. This result, which we formally prove in our working paper (Arora et al., 1996), is completely intuitive. It only requires that entry as an SEF has a fixed cost (corresponding to the cost of acquiring technical expertise), and that the price-cost margin (profit per unit of output) of an SEF decline with the number of SEFs in that sector.

The second effect is from the SEFs in the first world to the size of the developing country market. To see this, suppose that first world SEFs did not exist. Then, apart from relying on multinationals, either developing country firms would have to provide the services themselves or rely on domestic SEFs that may exist. In either case, developing country firms would face very high costs. Having fewer SEFs to choose from increases search costs, lowers the bargaining power of the buyer, and reduces the likelihood of getting a more advanced or appropriate technology. As a result, the expected surplus of setting up a plant would be lower, and this implies lower investment in chemical plants. Given the high transportation costs for many chemical products, this would imply slower growth of chemicals, and industrial activity more generally.

This simple story relies strongly on the assumption that the critical input is easily 'tradable' across countries. It is then important to understand why is this input tradable. Even though an ammonia plant in the US is a different object from an ammonia plant in India, what remains unchanged are the basic principles of how an ammonia plant should be designed and engineered. Clearly, applying what one has learned in one place in another is not always easy, and the literature has shown that technology transfer is not costless (e.g., Teece, 1977). Such costs are likely to depend on the very nature of the

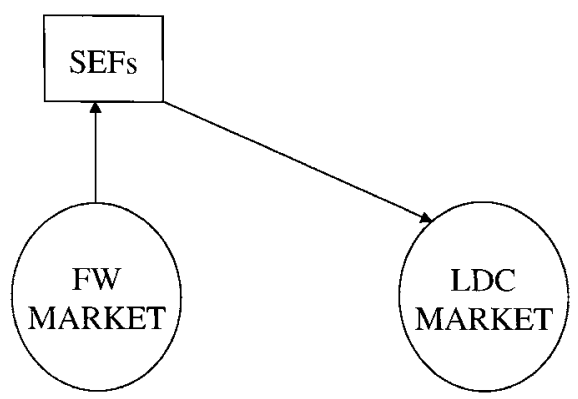

Fig. 1. The transmission of growth impulses. 
knowledge embodied in the technology (Arrow, 1962), with tacit and less articulated knowledge being more difficult to transfer, but also on the "absorptive capacity" of the recipient firm (Cohen and Levinthal, 1989). However, the important point is that the transfer cost be smaller than the cost of developing the technology, an assumption that fits especially well in the context of engineering services. It is in this sense that the fixed cost of developing or inventing the technology is paid by the industries or countries that emerge earlier, while the industries or countries that come later pay only the marginal cost.

This also points to the importance of independent suppliers that do not produce the downstream product. $^{4}$ Downstream producers (chemical firms) are less likely to sell technology or other key inputs to other producers. Unlike upstream specialists (SEFs), they have to offset the gains from selling technology against the lost profits in the downstream product. Thus, in addition to the classical gains from productivity improvements, specialization and division of labor can have other benefits for industrial growth, which are sometimes overlooked.

\subsection{The model}

We develop a simple stylized model to motivate our empirical analysis, which focuses on the investment decision of chemical firms in developing countries. We posit that the first world market for chemical process technology has already emerged and a division of labor achieved. In other words, we take as given the number of SEFs, $k$ that have entered the market for engineering services in the first world. It would be easy to endogenize $k$ and show that it increases with the size of the market in the first world (see Arora et al., 1996). We assume that first world SEFs can costlessly supply developing countries, with technology-specific costs already sunk. ${ }^{5}$ Therefore, the number of SEFs that can potentially serve the developing country market is equal to $k$. Note that $k$ is independent of the developing country market size. ${ }^{6}$ We also assume that SEFs are symmetric ex-ante.

\footnotetext{
${ }^{4}$ Such specialized suppliers are also present in other industries, such as steel and power plants, but the division of labor there is not as extensive and widespread as in chemicals. As discussed elsewhere, the nature of the chemical technology, the development of chemical engineering as a discipline, and events in the history of the industry are important reasons why SEFs are more prominent in chemicals (see Arora and Gambardella, 1998). Note also how the story of SEFs parallels that of the extensive division of labor that we find today in many high-tech industries like software or biotechnology.

${ }^{5}$ As we have discussed earlier, technology transfer is not costless (Teece, 1977). Our model can be easily generalized to one where SEFs have to bear two types of fixed costs: product-specific, which are already sunk, and country-specific, which have to be incurred for each country that the SEF supplies. Results are unchanged provided that product-specific fixed costs are larger than country-specific fixed costs. See our working paper for further details (Arora et al., 1996).

${ }^{6}$ Strictly speaking, this is true only if the size of the LDC market is too small to induce further entry of SEFs. Also, we are assuming that first-world SEFs are not fully forward-looking. Else they would anticipate that a given LDC market would arise in the future and they would adjust their optimal investment (entry) decision. Neither assumption is formally necessary for LDCs to benefit from first world SEFs.
} 
Turning to the developing country market, we denote by $N$ the exogenous potential demand for chemical plant for a particular type in a given market. For simplicity, assume that the investment decision of a given chemical company in a given plant is independent of the investment decision in any other plant, even by the same user. When considering whether to invest in a new plant, each downstream firm has three choices. It can either not invest (and hence earn zero), or it can 'buy' engineering services from SEFs, or it can 'make' (engineer) the plant by itself. We denote by $\Omega=\{B, M, \phi\}$ the set of possible alternatives where $B$ stands for a plant bought from the upstream technological sector, $M$ for in-house engineering and $\phi$ for no investment. Also, let $S=B \cup M$ where $S$ denotes the observed size of the developing country market.

Let $\pi_{n}$ be the net surplus to a given buyer (chemical firm) from a plant supplied by the SEF $n, n=\{1,2, \ldots, k\}$. We assume that $\pi_{n}$ is ex-post idiosyncratic to the buyer-seller match. Therefore, $\pi_{n}$ is an iid. random variable with distribution function $G(\cdot)$. Also, let $z=\operatorname{Max}\left\{\pi_{1}, \pi_{2}, \ldots, \pi_{k}\right\}$. Then, $\operatorname{Pr}(z \leq t)=G^{k}(t)$, is the probability that the net surplus from running a plant bought from the upstream sector is less or equal than $t$. Finally, for any chemical firm let $a$ be the net surplus from an in-house technology and let $a$ be distributed according to the cumulative function $F(\cdot)$.

If $\operatorname{Max}\{z, a\} \geq 0$, the firm will invest in the plant. Moreover, if $z \geq a$ the firm will buy the engineering services; and if $z<a$ it will supply them in-house. We show first that the greater the number of SEFs, the greater is the number of plants that are constructed. The expected number of plants, $E$ (size), in a given developing country is:

$$
E(\text { size })=N[\operatorname{Pr}(\Omega=S)]
$$

where

$$
\operatorname{Pr}(\Omega=S)=1-F(0) G^{k}(0)
$$

Result 1. The total investment in a given developing country market, $E($ size $)$, is increasing in the number of (potential) technology suppliers, $k$.

Proof. By taking first differences with respect to $k$ in expression (2) we get:

$$
E(\text { size } \mid k+1)-E(\text { size } \mid k)=N\left\{F(0) G^{k}(0)[1-G(0)]\right\}>0
$$

It is also easy to see from Eq. (3) that $E$ (size) is concave in $k$, so that the marginal increase in investment diminishes with $k$. We next show that SEFs increase the probability of 'buy' and decrease the probability of 'make'. One can write the expected number of plants that are bought from the upstream technological sector, $E$ (buy), and the expected number of plants that are made in house by the chemical firms, $E$ (make):

$$
\begin{aligned}
& E(\text { buy })=N[\operatorname{Pr}(\Omega=B)] \\
& E(\text { make })=N[\operatorname{Pr}(\Omega=M)]
\end{aligned}
$$

where

$$
\operatorname{Pr}(\Omega=B)=1-F(0) G^{k}(0)-\int_{0}^{\infty} G^{k}(t) \mathrm{d} F(t)
$$


and

$$
\operatorname{Pr}(\Omega=M)=\int_{0}^{\infty} G^{k}(t) \mathrm{d} F(t)
$$

Using $\Delta E$ (buy) $/ \Delta k \equiv E$ (buy $\mid k+1)-E$ (buy $\mid k$ ) and similarly for $\Delta E($ size $) / \Delta k$ and $\Delta E($ make $) / \Delta k$ we can state our second result:

Result 2. $(\Delta E$ (buy) $/ \Delta k)>(\Delta E($ size $) / \Delta k)>0>(\Delta E($ make $) / \Delta k)$.

Proof. Note that $(\Delta E$ (buy) $/ \Delta k)=(\Delta E($ size $) / \Delta k)+(\Delta E$ (make) $/ \Delta k)$. Then, by taking first differences in expression (4) with respect to $k$ one obtains:

$$
\frac{\Delta[E(\text { buy })]}{\Delta k}=\frac{\Delta[(\text { size })]}{\Delta k}-\int_{0}^{\infty}[G(t)-1] G^{k}(t) \mathrm{d} F(t)>\frac{\Delta[E(\text { size })]}{\Delta k}
$$

Our final result develops an implication of the theory that is not obvious and so provides an additional test for the theory itself. Consider any variable $x$ that increases the net surplus from running an in-house engineered plant (i.e., increases the profitability of the 'make' strategy). Formally, we assume that $x_{1} \geq x_{2}$ implies $F\left(t ; x_{1}\right) \leq F\left(t ; x_{2}\right)$ for any $t$. For instance, $x$ is likely to be higher the greater is the level of in-house technological capability of the chemical firm. Thus, MNEs are likely to have a higher value of $x$ than developing country chemical firms. Intuitively, SEFs ought to be more valuable for developing country firms than for MNEs. Our third result formalizes this intuition.

Result 3.

$$
\left.\frac{\Delta[E(\text { size })]}{\Delta k}\right|_{x=x_{1}} \leq\left.\frac{\Delta[E(\text { size })]}{\Delta k}\right|_{x=x_{2}} \text { for all } x_{1} \geq x_{2} .
$$

Proof. One can rewrite

$$
\left.\frac{\Delta[E(\text { size })]}{\Delta k}\right|_{x=x_{1}}-\left.\frac{\Delta[E(\text { size })]}{\Delta k}\right|_{x=x_{2}}
$$

as

$$
G^{k}(0)[1-G(0)]\left[F\left(0 ; x_{1}\right)-F\left(0 ; x_{2}\right)\right]
$$

which is unambiguously non-positive.

\section{Empirical analysis}

\subsection{Sample and variables}

To test our model we use data on 38 developing countries and 136 chemical process technologies. This gave us 5168 'markets', where the unit of observation is a process- 
country pair. Plant-level data on the 136 chemical processes were obtained from a comprehensive database, Chemical Age Project File, which covers all new chemical plants (over 20000 in all) announced all over the world during 1980-1989. The database and the construction of the variables used in the empirical analysis are described in more detail in Appendix A. Our 38 countries (listed in Appendix A) are all the developing countries for which we could obtain complete data from two main sources: UN Statistical Yearbook, and Barro and Lee (1994). These countries cover about $80 \%$ of all the chemical plants located in developing countries in the database. In what follows we define 'first world' to be Western Europe, USA, Canada, Japan, Australia, and New Zealand. All the other countries are developing countries.

We constructed the following variables. SIZE $i j$ is the total investment in millions of US dollars in our 136 processes $i$ and 38 countries $j$. This is obtained by multiplying the number of plants in $i j$ by the average investment cost of a plant in process $i$ in all developing countries. Similarly, we construct $\mathrm{BUY}_{i j}$ and $\mathrm{MAKE}_{i j}$, which are the total dollar investments in plants whose engineering services are bought from an unaffiliated contractor, and the total investment in plants whose engineering services are made in-house (or by an affiliated SEF). DOM $i j$ and $\mathrm{MNE}_{i j}$ are the total dollar investments by developing country and multinational firms, respectively. ${ }^{7}$

SIZE_FW $\mathrm{FW}_{i}$ is the total value of investment in process $i$ in the first world. This is obtained by multiplying the total number of plants in process $i$ in the first world by COST_FW ${ }_{i}$, the average investment cost of a plant in process $i$ in the first world. SEF_FW ${ }_{i}$ is the number of firms (SEFs) that provide engineering services in process $i$ in the first world.

We constructed two other process-specific variables, $\mathrm{NOVEL}_{i}$ and $\mathrm{PROCPAT}_{i}$. They are two measures of the nature of the technology. PROCPAT $i$ is the total number of 1976-1997 US patents granted for the chemical process $i$. It covers only the patents relating to the process itself rather than to the use of the output produced by the process. PROCPAT $_{i}$ is a good measure of the complexity of the process technology, and of the potential for multiple inputs, pathways, and final product qualities. NOVEL ${ }_{i}$ is the growth rate between the two periods 1986-1995 and 1976-1985 of all the US patents whose title contained the exact name of the process $i$. Unlike PROCPAT ${ }_{i}, \mathrm{NOVEL}_{i}$ does not distinguish between process and product patents. Thus, for instance, this variable also includes the development of new uses of the product. NOVEL ${ }_{i}$ is then likely to be a measure of the rate of technological change. We use these two variables to control for the maturity and complexity of the technology. Our objective here is to rule out the possibility that the estimated coefficient of SEF_FW ${ }_{i}$ reflects the effect that developing countries are more likely to invest in older and more mature processes. In

\footnotetext{
${ }^{7}$ Actual investment costs are reported for about $40 \%$ of the plants and these were used to calculate the average cost per plant in a given process. We assume that the BUY and MAKE plants and the DOM and MNE plants have the same average cost because we lack enough observations with cost figures to separately estimate the average cost for them. However, for the few processes in which we had enough observations to compute separate average costs, they were not statistically different across MAKE and BUY, and DOM and MNE.
} 
turn, these two variables may also help to control for differences in the technology transfer costs.

In addition, the database classifies plants into 21 chemical sub-sectors, which we grouped in nine sector dummies (listed in Appendix A). Our country-specific variables include measures like GDP, population, energy consumption, openness, and human capital, and are listed in Table 1 along with their source. Table 2 presents descriptive statistics for the variables used in our analysis.

\section{2. $S I Z E_{i j}, B U Y_{i j}$, and $M A K E_{i j}:$ specification and empirical results}

We begin our empirical analysis by estimating three equations linking $\mathrm{SIZE}_{i j}, \mathrm{BUY}_{i j}$, and $\mathrm{MAKE}_{i j}$ to the number of first world SEFs. We employed a logarithmic specification of the form

$$
\log \left(X_{i j}\right)=\text { const }+a \mathbf{Y}_{j}+b \mathbf{Z}_{i}+e_{i j}
$$

where $X_{i j}$ is $\mathrm{SIZE}_{i j}, \mathrm{BUY}_{i j}$, or $\mathrm{MAKE}_{i j}, \boldsymbol{Y}_{j}$ is a vector of country-specific characteristics, $\boldsymbol{Z}_{i}$ is a vector of process specific characteristics, and $e_{i j}$ is an error term. We note that the results are robust to alternative specifications such as linear or exponential. A logarithmic specification allows the marginal effect of SEFs to diminish with the number of SEFs, consistent with the model in Section 3. Bresnahan and Reiss (1991) have also shown that four to five suppliers in a market may be enough to make the

Table 1

List of country characteristics

\begin{tabular}{|c|c|}
\hline$\overline{\mathrm{GDP}}_{j}$ & $\begin{array}{l}\text { Real GDP of country in } 1985 \text { in billions of US dollars. Obtained by multiplying } \\
\text { per capita GDP of country (Barro-Lee) by population }\end{array}$ \\
\hline $\mathrm{POP}_{j}$ & Population of country in 1985 in millions (Barro-Lee) \\
\hline ENERGY $_{j}$ & $\begin{array}{l}\text { Total energy consumption of country (1985-1987 average) in thousand metric } \\
\text { tons of coal equivalent (UN Statistical Yearbook) }\end{array}$ \\
\hline $\mathrm{AREA}_{j}$ & 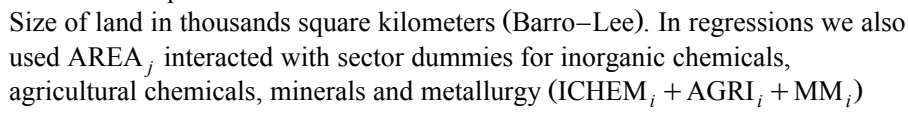 \\
\hline $\mathrm{HKAP}_{j}$ & $\begin{array}{l}\text { Human Capital. Average schooling years of population over } 25 \text { in the country } \\
\text { (Barro-Lee) }\end{array}$ \\
\hline $\mathrm{OPEN}_{j}$ & Ratio of exports plus imports to GDP of country in 1985 (Barro-Lee) \\
\hline $\operatorname{DOIL}_{i j}$ & $\begin{array}{l}\text { Dummy for countries with oil reserves interacted with dummy for processes in } \\
\text { the oil-refining sector. Countries with oil reserves: Algeria, Argentina, } \\
\text { Brazil, China, Colombia, Ecuador, Egypt, India, Indonesia, Iran, Iraq, } \\
\text { Kuwait, Malaysia, Mexico, Nigeria, Saudi Arabia, Syria, Venezuela } \\
\text { (Main countries with oil reserves listed in World Atlas, 1990) }\end{array}$ \\
\hline DGAS $_{i j}$ & $\begin{array}{l}\text { Dummy for countries with natural gas reserves interacted with dummy for } \\
\text { processes in the gas-processing sector. Countries with natural gas reserves: } \\
\text { Algeria, Argentina, Indonesia, Mexico, Venezuela (Main countries } \\
\text { with natural gas reserves listed in World Atlas, 1990.) }\end{array}$ \\
\hline $\begin{array}{l}\text { Geographical area } \\
\text { dummies }\end{array}$ & Africa, Eastern Europe, Middle East, Central and South America, Far East. \\
\hline
\end{tabular}


Table 2

Descriptive statistics

\begin{tabular}{|c|c|c|c|c|c|}
\hline Variable & $\begin{array}{l}\text { Number of } \\
\text { observations }\end{array}$ & Mean & Std. dev. & Min & Max \\
\hline$\overline{\mathrm{SIZE}_{i j}^{\mathrm{a}}}$ & 5168 & 76.4 & 430.5 & 0 & $17,751.7$ \\
\hline $\mathrm{BUY}_{i j}^{\mathrm{a}}$ & 5168 & 73.6 & 421.8 & 0 & $17,751.7$ \\
\hline MAKE $_{i j}^{\mathrm{a}}$ & 5168 & 2.8 & 33.3 & 0 & 1321.1 \\
\hline $\mathrm{DOM}_{i j}^{\mathrm{a}}$ & 5168 & 61.6 & 364.8 & 0 & $13,313.7$ \\
\hline $\mathrm{MNE}_{i j}^{\mathrm{a}}$ & 5168 & 14.8 & 128.6 & 0 & 4437.9 \\
\hline $\mathrm{SIZE}_{-} \mathrm{FW}_{i}^{\mathrm{a}}$ & 136 & 2733.1 & 6291.3 & 2.0 & $45,555.6$ \\
\hline $\mathrm{COST}_{2} \mathrm{FW}_{i}^{\mathrm{a}}$ & 136 & 76.2 & 146.2 & 0.8 & 1190 \\
\hline $\mathrm{SEF}_{2} \mathrm{FW}_{i}$ & 136 & 11.96 & 11.78 & 0 & 60 \\
\hline $\mathrm{NOVEL}_{i}$ & 136 & 0.16 & 0.65 & -0.78 & 3.6 \\
\hline $\mathrm{PROCPAT}_{i}$ & 136 & 61.19 & 60.65 & 1 & 345 \\
\hline $\mathrm{SLARGECO}_{i}$ & 136 & 0.50 & 0.22 & 0 & 1 \\
\hline SGREEN $_{i}$ & 136 & 0.63 & 0.22 & 0.19 & 1 \\
\hline $\mathrm{GDP}_{j}^{\mathrm{b}}$ & 38 & 171.28 & 323.40 & 19.63 & 1918.79 \\
\hline $\mathrm{POP}_{j}^{\mathrm{b}}$ & 38 & 84.90 & 204.40 & 1.70 & 1059.50 \\
\hline ENERGY $_{j}^{\mathrm{b}}$ & 38 & 61.26 & 126.70 & 1.48 & 765.18 \\
\hline $\mathrm{AREA}_{j}^{\mathrm{b}}$ & 38 & 1311.4 & 2039.4 & 1.0 & 9537.0 \\
\hline $\mathrm{OPEN}_{j}^{\mathrm{b}}$ & 38 & 0.46 & 0.47 & 0.1 & 2.64 \\
\hline $\mathrm{HKAP}_{j}^{\mathrm{b}}$ & 38 & 4.62 & 2.15 & 0.91 & 10.75 \\
\hline
\end{tabular}

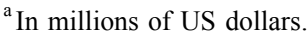

${ }^{\mathrm{b}}$ See Table 1.

market competitive (the average number of SEFs in our sample is 12). This suggests a functional form that accounts for the diminishing returns of an extra supplier. ${ }^{8}$

As country-specific characteristics we used measures of the economic size of the country $\left(\log \left(\mathrm{GDP}_{j}\right), \log \left(\mathrm{POP}_{j}\right), \log \left(\mathrm{ENERGY}_{j}\right), \log \left(\mathrm{AREA}_{j}\right)\right)$, measures of human capital $\left(\mathrm{HKAP}_{j}\right)$ and openness to trade $\left(\mathrm{OPEN}_{j}\right)$, and geographic area dummies. We also used dummy variables for the presence in the country of oil or gas reserves and interacted them with the sector dummies for oil refining plants and gas plants $\left(\mathrm{DOIL}_{i j}\right.$ and $\left.\mathrm{DGAS}_{i j}\right)$. We also interacted $\log \left(\mathrm{AREA}_{j}\right)$ with a dummy for the three sectors inorganic chemicals, agricultural chemicals, and minerals and metallurgy $\left(\mathrm{ICHEM}_{i}+\right.$ $\mathrm{AGRI}_{i}+\mathrm{MM}_{i}$ ). This is because larger countries are more likely to possess natural resources that are the basis for production in inorganic chemicals and minerals. Similarly, it is more likely that bigger countries have greater demand for agricultural chemicals. Apart from $\log \left(\mathrm{SEF}_{-} \mathrm{FW}_{i}\right)$, we used the following process-specific characteristics as controls: sector dummies, $\log \left(\right.$ SIZE_FW $\left.{ }_{i}\right), \log \left(\mathrm{COST}_{-} \mathrm{FW}_{i}\right), \log \left(\mathrm{PROCPAT}_{i}\right)$, and NOVEL .

Table 3 presents the results of our OLS estimations of Eq. (9). The estimated elasticities, with respect to $\mathrm{SEF}-\mathrm{FW}_{i}$, of $\mathrm{SIZE}_{i j}$ and $\mathrm{BUY}_{i j}$ are large and statistically

\footnotetext{
${ }^{8}$ Since our dependent variables can take zero values, we redefined $\operatorname{SIZE}_{i j}$ as $1+\mathrm{SIZE}_{i j}$, and to keep with the adding up restriction we redefined $\mathrm{BUY}_{i j}$ and $\mathrm{MAKE}_{i j}$ as $0.5+\mathrm{BUY}_{i j}$ and $0.5+\mathrm{MAKE}_{i j}$. This is just to make the results of the three equations comparable. Using $1+\mathrm{BUY}_{i j}$ and $1+\mathrm{MAKE}_{i j}$ did not produce any significant difference.
} 
Table 3

Determinants of total investment, "buys" and "makes": OLS and Tobit Estimates $\log \left(X_{i j}\right)=$ const $+a \boldsymbol{Y}_{j}+b \boldsymbol{Z}_{i}+e_{i j}$

\begin{tabular}{|c|c|c|c|c|c|c|}
\hline & \multicolumn{3}{|l|}{ OLS } & \multicolumn{3}{|l|}{ TOBIT } \\
\hline & $\overline{\mathrm{SIZE}_{i j}}$ & $\mathrm{BUY}_{i j}$ & $\mathrm{MAKE}_{i j}$ & $\overline{\operatorname{SIZE}_{i j}}$ & $\mathrm{BUY}_{i j}$ & $\mathrm{MAKE}_{i j}$ \\
\hline Constant & $-10.57 * *(1.17)$ & $-11.82 * *(1.31)$ & $-3.42 * *(0.45)$ & $-36.78 * *(4.24)$ & $-40.52 * *(4.91)$ & $-141.35 * *(24.93)$ \\
\hline $\operatorname{DOIL}_{i j}$ & $0.44 * *(0.14)$ & $0.47 * *(0.16)$ & $0.11^{*}(0.05)$ & $0.91 *(0.45)$ & $1.04 *(0.52)$ & $2.15(1.98)$ \\
\hline $\log \left(\mathrm{HKAP}_{j}\right)$ & $-0.13(0.13)$ & $-0.05(0.03)$ & $-0.05(0.05)$ & $0.18(0.47)$ & $0.22(0.55)$ & $5.50(2.87)$ \\
\hline $\log \left(\mathrm{GDP}_{i}\right)$ & $0.40 * *(0.12)$ & $0.37 * *(0.14)$ & $0.21^{* *}(0.05)$ & $0.88 *(0.43)$ & $0.78(0.50)$ & $7.41 * *(2.32)$ \\
\hline $\log \left(\mathrm{POP}_{j}\right)$ & $-0.10(0.09)$ & $-0.07(0.10)$ & $-0.08 *(0.04)$ & $-0.33(0.30)$ & $-0.26(0.35)$ & $-2.04(1.92)$ \\
\hline $\begin{array}{l}\left(\mathrm{ICHEM}_{i}+\mathrm{AGRI}_{i}+\mathrm{MM}_{i}\right) \times \\
\log \left(\mathrm{AREA}_{i}\right)\end{array}$ & $0.13^{* *}(0.03)$ & $0.15^{* *}(0.04)$ & $0.01(0.01)$ & $0.50 * *(0.13)$ & $0.56^{* *}(0.15)$ & $0.90(0.62)$ \\
\hline $\mathrm{OPEN}_{j}$ & $0.29^{*}(0.13)$ & $0.39 * *(0.07)$ & $-0.12 *(0.05)$ & $0.97^{*}(0.46)$ & $1.30 *(0.52)$ & $-11.55^{* *}(3.73)$ \\
\hline Log $\left(\right.$ SIZE_FW $\left.{ }_{i}\right)$ & $0.38 * *(0.05)$ & $0.41 * *(0.06)$ & $0.07 * *(0.02)$ & $0.91 * *(0.19)$ & $0.96 *(0.22)$ & $4.18^{* *}(0.96)$ \\
\hline $\log \left(\operatorname{COST} \_\mathrm{FW}_{i}\right)$ & $-0.32 * *(0.06)$ & $-0.36^{* *}(0.06)$ & $-0.07^{* *}(0.02)$ & $-0.99 * *(0.20)$ & $-1.09^{* *}(0.23)$ & $-4.64^{* *}(1.07)$ \\
\hline NOVEL $_{i}$ & $-0.14 * *(0.05)$ & $-0.16 * *(0.05)$ & $-0.03(0.02)$ & $-0.37 * *(0.15)$ & $-0.42 *(0.17)$ & $-1.13(0.71)$ \\
\hline $\log \left(\mathrm{PROCPAT}_{i}\right)$ & $-0.14 * *(0.03)$ & $-0.16^{* *}(0.03)$ & $0.00(0.01)$ & $-0.43^{* *} 0.10$ & $-0.50 * *(0.12)$ & $-0.10(0.48)$ \\
\hline Number of observations & 5168 & 5168 & 5168 & 5168 & 5168 & 5168 \\
\hline Share of positive observations & 0.33 & 0.27 & 0.03 & 0.33 & 0.27 & 0.03 \\
\hline
\end{tabular}

Standard errors in parenthesis. All regressions include sector dummies and dummies for geographical areas of country.

* Significant at $5 \%$ level.

** Significant at $1 \%$ level. 
significant ( 0.46 and 0.52 , respectively). By contrast, the elasticity of $\mathrm{MAKE}_{i j}$ is very small, and insignificantly different from zero. As predicted by Result 2 in our model, the effect of SEFs is greater for the 'buys' than for the chemical plant investments as a whole, and the effect on the 'makes' is almost zero.'

Since our dependent variables, $\mathrm{SIZE}_{i j}, \mathrm{BUY}_{i j}$ and $\mathrm{MAKE}_{i j}$, are non-negative, we also estimate a Tobit specification, whose results are also reported in Table 3. Notice that the signs of the explanatory variables in the Tobit specifications are similar to the ones in the OLS specifications. A more sophisticated estimation procedure that addresses the problem generated by the many zeros is presented in Section 4.3.

The basic result of Table 3 is that the effects of SEF_FW ${ }_{i}$ on SIZE $_{i j}$ and BUY $i j$ are of sizable magnitude and they are statistically significant in spite of our extensive controls for the size of the chemical process and country markets. Note also that our measures of market size (e.g., $\mathrm{GDP}_{j}, \mathrm{ENERGY}_{j}, \mathrm{AREA}_{j}, \mathrm{SIZE}_{-} \mathrm{FW}_{i}$ ) are generally significant in all "three equations. Finally, in all three equations, the cost of a 'typical' plant $\left(\mathrm{COST}_{-} \mathrm{FW}_{i}\right)$, and our measures of technological change and complexity $\left(\mathrm{NOVEL}_{i}\right.$ and PROCPAT $_{i}$ ) have the expected sign. As predicted by the product lifecycle theory, more costly and technological advanced or complex processes, the smaller the investments in developing countries.

\subsection{Measurement error, unobserved heterogeneity, and minimum investment threshold}

Our empirical procedure in the previous section raises three important issues. First, our measure of potential suppliers ignores the possibility that an SEF operating in a certain market could be a potential supplier for a related process. Our assumption is certainly plausible ${ }^{10}$ but if invalid, it implies that $\mathrm{SEF}_{-} \mathrm{FW}_{i}$ is measured with error. If so, our estimates are likely to be biased towards zero, and the true effect is likely to be larger than the estimated effect. As a robustness check, we estimated a specification (not reported here) where we use SEFs operating in an entire sector (e.g., synthetic fibers) in the first world as being potential suppliers for all processes (e.g., polyester and nylon) belonging to that sector. The estimated impacts of the number of first world SEFS were qualitatively similar to those reported in Table 3 . Therefore, our measure of the supply of SEFs is not likely to be key to our empirical results.

A more important problem is that we are likely to measure $N_{i j}$, the potential size of the market, with error. If this error is correlated with the number of first world SEFs our estimates will be biased. For instance, if unobserved increases in the size of the developing country markets induce more SEFs to enter to supply those technologies, an endogeneity bias arises. However, both qualitative and quantitative evidence suggests that our estimates are not seriously biased.

\footnotetext{
${ }^{9}$ The relatively large number of "zero" observations in $\mathrm{MAKE}_{i j}$ imply that the estimates of this equation should be interpreted with caution.

${ }^{10}$ For instance, our database shows that three different sets of SEFs supply the markets for three different types of polyethylene-high-density, low-density, and linear low-density polyethylene-with very little overlap.
} 
Most SEFs, and virtually all the major ones in the US, Europe and Japan, were founded before World War II or right afterwards, and most chemical process technologies were developed 20 to 40 years ago when the developing country chemical markets were still quite small or non-existent - and by that time SEFs had already accumulated considerable expertise in these fields (Arora and Gambardella, 1998). Moreover, first world SEFs maintain strong linkages with their country of origin, and from our database we confirmed that it is rare for SEFs to supply engineering services to developing countries in a process unless they also do so in their home markets. Nonetheless, it is still possible that the growth of developing country markets induces further accumulation of expertise by SEFs or that developing country demand prevented some SEFs from exiting the industry. If so, unobserved variations in developing country demand for chemical plants are correlated with our measure of SEFs.

The standard approach in this case is to find instruments for first world SEFs. However, distinguishing among countries according to the extent to which they were open to the inflow of foreign technologies is difficult. Even countries like South Korea that have protected downstream markets have been open to imports of technology and engineering services. Aggregate measures of openness cannot capture this subtlety. Further, the rise of West European and Japanese SEFs has made the market for chemical processes a truly global market. Even a country like Libya, which is not directly supplied by American SEFs, is served by a large number of European and Japanese SEFs. In short, there seems to be insufficient cross-country variation in the effective supply of SEFs for this to be a useful way to identify their impact.

By contrast, differences across processes in the nature of the technology have been an important source of variations in the number of SEFs. ${ }^{11}$ We use two instruments that exploit the variation in the composition of first world demand for SEFs (recall also that we control for the size of the first world market). SLARGECO $i$ is the share of total investment in the first world in process $i$ undertaken by the 200 largest non-oil companies. SGREEN ${ }_{i}$ is the ratio between the number of greenfield plants and the sum of greenfield, expanded and revamped plants in process $i$ in the first world. The former instrument, $\mathrm{SLARGECO}_{i}$, is justified by the fact that the top chemical companies are more likely to have the capabilities to produce their engineering services in-house.

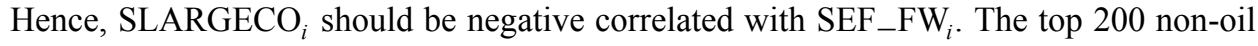
companies include virtually all the important chemical companies in the first world. We exclude oil companies because historically oil companies have made systematic use of SEFs (see Arora et al., 1998). ${ }^{12}$

The second instrument, $\mathrm{SGREEN}_{i}$, has a similar justification. Greenfield plants are likely to be more complex projects than mere expansions or revamping of existing capacities. As a result, they are more likely to require the work of specialist contractors. It is also likely that the company that owns the plant has greater knowledge about the

\footnotetext{
${ }^{11}$ For instance, the scientific basis for some processes is better understood and codified, which encourages specialization and increases the number of SEFs.

${ }^{12}$ We also tried the share of first world plants by the chemical (and/or oil) companies among the top 50 and top 100 companies in terms of first world plants. Our results are robust to such variations.
} 
idiosyncrasies of the plant, and thus, it is in a better position to expand or revamp.

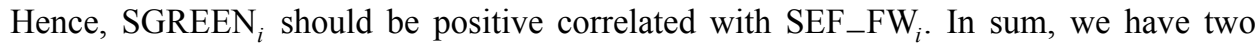
instruments that are likely to affect the demand for SEF services in the first world but are uncorrelated with unmeasured variations in market size in developing countries. Table 4 shows, as expected, that first world SEFs are negatively correlated with the share of large firms, and positively correlated with the share of greenfield plants.

Table 5 presents the results of a GMM estimation of the $\operatorname{SIZE}_{i j}$ equation. For ease of comparison, we also reports the OLS regression for $\mathrm{SIZE}_{i j}$ from Table 3, and the chi-square statistics of a Hausman specification test comparing the OLS and GMM estimates (see Hausman, 1978, for details). Table 5 shows that the potential endogeneity bias of SEF_FW ${ }_{i}$ is quite modest. Our GMM estimator of the elasticity with respect to SEF_FW ${ }_{i}$ is 0.45 , which is very close to our original OLS estimate of 0.46 . To get a sense of the order of magnitude of the impact, one can use the GMM estimate to compute the effect of one additional SEF in a typical process market on the expected total dollar value of investment in the developing countries in that process market. Average investment in a process-country market is US\$76.4 million, whereas the average number of first world SEFs in a process market is 12 . Therefore, an addition SEF would increase investment by US $\$(0.45 \cdot 76.4 / 12)$ million $=$ US $\$ 2.86$ million. For our set of 38 LDCs this amounts to US\$109 million, i.e., little less than one extra plant over the 10-year period in the 38 countries (the average cost of a plant in LDCs is about

Table 4

OLS estimation: Dependent variable-Log $\left(\mathrm{SEF} \_\mathrm{FW}_{i}\right)$

\begin{tabular}{|c|c|c|}
\hline Variable & Coefficient & Std. Error \\
\hline Constant & $-0.95^{*}$ & 0.38 \\
\hline \multicolumn{3}{|l|}{ SECTOR DUMMIES: } \\
\hline Agriculture & 0.23 & 0.26 \\
\hline Gas & 0.43 & 0.24 \\
\hline Oil Refining & $0.60 * *$ & 0.23 \\
\hline Organic chemicals & 0.00 & 0.24 \\
\hline Petrochemicals & 0.35 & 0.22 \\
\hline Minerals and metallurgy & -0.24 & 0.26 \\
\hline Plastics and rubber & 0.15 & 0.26 \\
\hline Inorganic chemicals & 0.08 & 0.27 \\
\hline $\mathrm{NOVEL}_{i}$ & -0.15 & 0.08 \\
\hline $\log \left(\mathrm{PROCPAT}_{i}\right)$ & -0.03 & 0.05 \\
\hline SIZE_FW $_{i}$ & $0.79 * *$ & 0.06 \\
\hline SLARGECO $_{i}$ & $-0.65^{* *}$ & 0.27 \\
\hline SGREEN $_{i}$ & $0.45^{*}$ & 0.23 \\
\hline $\log \left(\mathrm{COST} \_\mathrm{FW}_{i}\right)$ & $-0.69^{* *}$ & 0.08 \\
\hline Number of observations & 136 & \\
\hline Adjusted $R^{2}$ & 0.73 & \\
\hline
\end{tabular}

Standard errors in parenthesis.

* Significant at 5\% level.

** Significant at $1 \%$ level. 
Table 5

Impact of first world SEFs on investment in chemical plant in developing countries SIZE $_{i j}$ : OLS, GMM and generalized Tobit estimates

\begin{tabular}{|c|c|c|c|c|}
\hline & \multirow[t]{2}{*}{ OLS } & \multirow[t]{2}{*}{ GMM } & \multicolumn{2}{|l|}{ Generalized Tobit } \\
\hline & & & $\operatorname{Prob}\left(\operatorname{SIZE}_{i j}>0\right)$ & $\operatorname{SIZE}_{i j}$ \\
\hline Constant & $-10.57^{* *}(1.17)$ & $-10.52 * *(1.11)$ & $-8.33^{* *}(1.00)$ & $-7.62(6.62)$ \\
\hline DOIL $_{i j}$ & $0.44 * *(0.14)$ & $0.43 * *(0.15)$ & $0.21 *(0.11)$ & $0.35^{*}(0.17)$ \\
\hline DGAS $_{i j}$ & $0.31(0.21)$ & $0.35(0.28)$ & $0.10(0.17)$ & $0.59 *(0.29)$ \\
\hline $\log \left(\mathrm{HKAP}_{j}\right)$ & $-0.13(0.13)$ & $-0.15(0.12)$ & $0.02(0.11)$ & $-0.13(0.22)$ \\
\hline $\log \left(\mathrm{GDP}_{j}\right)$ & $0.40 * *(0.12)$ & $0.39 * *(0.12)$ & $0.19(0.10)$ & $0.35^{*}(0.18)$ \\
\hline $\log \left(\mathrm{POP}_{j}\right)$ & $-0.10(0.09)$ & $-0.11(0.10)$ & $-0.05(0.07)$ & $-0.08(0.11)$ \\
\hline $\log \left(\right.$ ENERGY $\left._{j}\right)$ & $0.34 * *(0.06)$ & $0.35 * *(0.06)$ & $0.32(0.05)$ & $0.21(0.23)$ \\
\hline $\log \left(\operatorname{AREA}_{j}\right)$ & $0.08 *(0.04)$ & $0.08 *(0.04)$ & $0.06^{*}(0.03)$ & $0.01(0.08)$ \\
\hline $\begin{array}{l}\left(\mathrm{ICHEM}_{i}+\mathrm{AGRI}_{i}+\mathrm{MM}_{i}\right) \times \\
\log \left(\mathrm{AREA}_{j}\right)\end{array}$ & $0.13 * *(0.03)$ & $0.13 * *(0.03)$ & $0.10 * *(0.03)$ & $0.06(0.08)$ \\
\hline $\mathrm{OPEN}_{j}$ & $0.29 *(0.13)$ & $0.27 *(0.12)$ & $0.24 *(0.11)$ & $0.16(0.29)$ \\
\hline Log $($ SIZE_FW & $0.38 * *(0.05)$ & $0.37 * *(0.14)$ & $0.22 * *(0.05)$ & $0.19(0.19)$ \\
\hline $\log \left(\mathrm{COST} \_\mathrm{FW}_{i}\right)$ & $-0.32 * *(0.06)$ & $-0.31^{*}(0.13)$ & $-0.30(0.05)$ & $0.39(0.25)$ \\
\hline $\mathrm{NOVEL}_{i}$ & $-0.14^{* *}(0.05)$ & $-0.16^{* *}(0.05)$ & $-0.08 *(0.04)$ & $-0.13^{*}(0.06)$ \\
\hline $\log \left(\mathrm{PROCPAT}_{i}\right)$ & $-0.14^{* *}(0.03)$ & $-0.14^{* *}(0.03)$ & $-0.09^{* *}(0.02)$ & $-0.12(0.09)$ \\
\hline $\log \left(\mathrm{SEF} \_\mathrm{FW}_{i}\right)$ & $0.46^{* *}(0.05)$ & $0.45^{* *}(0.17)$ & $0.39^{* *}(0.05)$ & $0.52(0.28)$ \\
\hline $\begin{array}{l}\text { Hausman test statistic for } \\
\left.\text { Log(SEF_FW }{ }_{i}\right)\end{array}$ & & 0.00 & & \\
\hline Number of observations & 5168 & 5168 & 5168 & 1448 \\
\hline
\end{tabular}

Standard errors in parenthesis. All regressions include sector dummies and dummies for geographical areas of country. All variables and SLARGECO ${ }_{i}$ and SGREEN $_{i}$ used as instruments for $\log \left(\mathrm{SEF}_{-} \mathrm{FW}_{i}\right)$ in GMM: Hausman test statistic computed as the square of the difference between the OLS and GMM estimates, divided by the difference between their variances.

${ }^{*}$ Significant at $5 \%$ level.

** Significant at $1 \%$ level.

US\$119 million). Notice that this effect is larger for larger countries like India and China and smaller for smaller countries, as shown in Fig. 2.

Finally, a third econometric issue that we noted in Section 4.2 arises from the presence of a censored dependent variable. Indeed, $\mathrm{SIZE}_{i j}$ shows a very large fraction of 'zero' observations (about 70\%). In turn, a 'zero' observation has an economic interpretation. It is consistent with the idea that there exists a threshold level below which setting up a chemical plant is not economically profitable. To capture this additional subtlety we use a generalized Tobit model (see Amemiya, 1985). This procedure estimates simultaneously a Probit model where the regressors explain the probability to observe a positive value for the dependent variable and an OLS model where the regressors explain, for positive observations alone, the magnitude of the dependent variable. Implicitly this implies that the threshold below which investing is not profitable is allowed to vary across observations. Results of this specification are also reported in Table 5. The results imply that first world SEFs increase the probability of investment and, given the threshold, increase investment as well. 


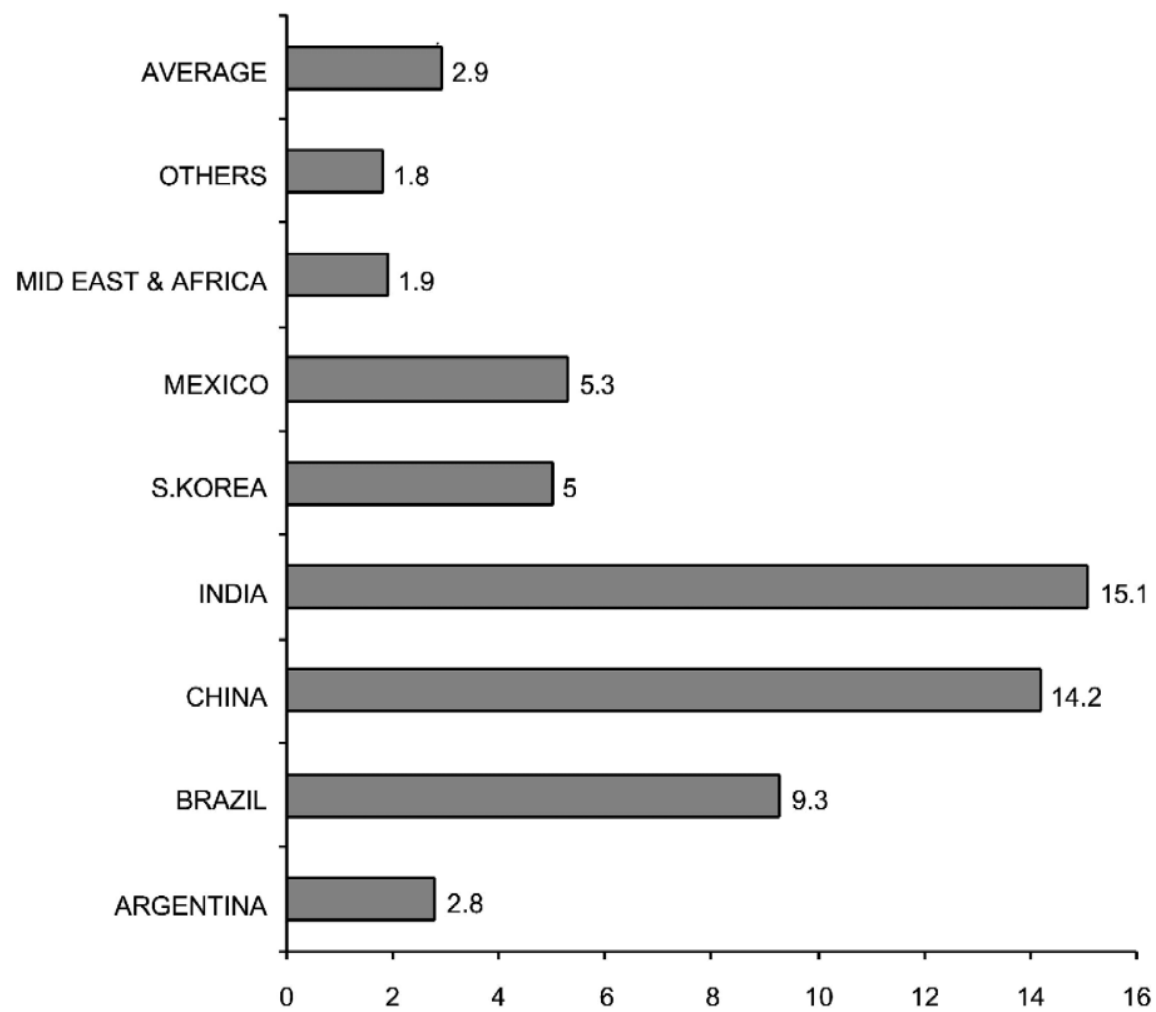

Fig. 2. Impact of an additional SEF. Additional investment per process, by country, in millions of US dollars.

\subsection{The differential effect of SEFs on developing country and multinational firms}

If our story is correct, then Result 3 implies that SEFs ought to benefit developing country firms much more than they benefit first world MNEs, which are likely to have substantial in-house technological capability. We estimated two equations for the total dollar investment by domestic firms and MNEs using the same specification and variables employed earlier. Table 6 presents the results of these estimations using least squares, method of moments and Tobit (OLS, GMM, Tobit), where in the GMM we use SLARGECO $_{i}$ and SGREEN $_{i}$ as instruments. ${ }^{13}$

The key result in Table 6 is that the estimates of the impact of first world SEFs are sizable and significant in the domestic firm equation, whereas they are small, statistically insignificant and even negative in the MNE equation, in all the three specifications

\footnotetext{
${ }^{13}$ The relatively sparse observations on MNE investment prevented us from estimating a generalized Tobit specification for this equation.
} 
Table 6

Investments by MNE and developing country firms in developing countries: $\mathrm{DOM}_{i j}, \mathrm{MNE}_{i j}-\mathrm{OLS}, \mathrm{GMM}$ and Tobit estimates log $\left(X_{i j}\right)=c o n s t+a \boldsymbol{Y}_{j}+b \boldsymbol{Z}_{i}+e_{i j}$

\begin{tabular}{|c|c|c|c|c|c|c|}
\hline & \multicolumn{3}{|l|}{$\mathrm{DOM}_{i j}$} & \multicolumn{3}{|l|}{$\mathrm{MNE}_{i j}$} \\
\hline & OLS & GMM & TOBIT & OLS & GMM & TOBIT \\
\hline Constant & $-10.20^{* *}(1.26)$ & $-10.11^{* *}(1.15)$ & $-46.01^{* *}(5.75)$ & $-4.66^{* *}(0.84)$ & $-4.91 *(0.95)$ & $-41.97 * *(9.54)$ \\
\hline $\mathrm{DOIL}_{i j}$ & $0.63 * *(0.15)$ & $0.61 * *(0.17)$ & $1.87^{* *}(0.59)$ & $-0.11(0.10)$ & $-0.11(0.10)$ & $-1.94(1.11)$ \\
\hline DGAS $_{i j}$ & $0.12(0.22)$ & $0.18(0.30)$ & $0.35(0.84)$ & $0.33^{*}(0.15)$ & $0.33(0.22)$ & $1.98(1.33)$ \\
\hline $\log \left(\mathrm{HKAP}_{j}\right)$ & $0.10(0.14)$ & $0.09(0.14)$ & $1.11(0.62)$ & $-0.37 * *(0.10)$ & $-0.37^{* *}(0.09)$ & $-2.89 *(1.14)$ \\
\hline $\log \left(\mathrm{GDP}_{j}\right)^{\prime}$ & $0.25(0.13)$ & $0.24(0.12)$ & $1.03(0.58)$ & $0.24 * *(0.08)$ & $0.24^{*}(0.10)$ & $0.66(0.98)$ \\
\hline $\log \left(\mathrm{POP}_{j}\right)$ & $0.04(0.10)$ & $0.03(0.10)$ & $-0.24(0.40)$ & $-0.18^{* *}(0.06)$ & $-0.18 * *(0.07)$ & $-1.32(0.73)$ \\
\hline $\log \left(\mathrm{ENERGY}_{j}\right)$ & $0.33^{* *}(0.07)$ & $0.34 * *(0.06)$ & $1.42^{* *}(0.31)$ & $0.14^{* *}(0.05)$ & $0.14^{* *}(0.04)$ & $2.51 * *(0.57)$ \\
\hline $\log \left(\mathrm{AREA}_{j}\right)$ & $0.11 * *(0.04)$ & $0.11 * *(0.04)$ & $0.42 *(0.17)$ & $-0.00(0.03)$ & $-0.00(0.02)$ & $0.09(0.31)$ \\
\hline $\begin{array}{l}\left(\mathrm{ICHEM}_{i}+\mathrm{AGRI}_{i}+\mathrm{MM}_{i}\right) \times \\
\log \left(\mathrm{AREA}_{j}\right)\end{array}$ & $0.14^{* *}(0.04)$ & $0.14 * *(0.03)$ & $0.70 * *(0.18)$ & $0.04(0.02)$ & $0.04(0.02)$ & $0.33(0.27)$ \\
\hline $\mathrm{OPEN}_{j}$ & $0.32 *(0.14)$ & $0.31 *(0.13)$ & $0.85(0.63)$ & $0.06(0.09)$ & $0.06(0.08)$ & $0.92(1.05)$ \\
\hline $\log \left(\right.$ SIZE_FW $\left.{ }_{i}\right)$ & $0.38 * *(0.06)$ & $0.34^{*}(0.15)$ & $1.10 * *(0.25)$ & $0.23 * *(0.04)$ & $0.43 * *(0.10)$ & $2.33 * *(0.44)$ \\
\hline $\log \left(C O S T \_F_{i}\right)$ & $-0.33^{* *}(0.06)$ & $-0.29 *(0.13)$ & $-1.18^{* *}(0.27)$ & $-0.22 * *(0.04)$ & $-0.40 * *(0.09)$ & $-2.73 * *(0.48)$ \\
\hline $\mathrm{NOVEL}_{i}$ & $-0.15^{* *}(0.05)$ & $-0.16 *(0.06)$ & $-0.43^{*}(0.19)$ & $-0.08^{*}(0.03)$ & $-0.13 * *(0.04)$ & $-0.90^{*}(0.37)$ \\
\hline $\log \left(\mathrm{PROCPAT}_{i}\right)$ & $-0.16 * *(0.03)$ & $-0.15^{* *}(0.03)$ & $-0.60^{* *}(0.13)$ & $-0.02(0.02)$ & $-0.02(0.02)$ & $-0.18(0.23)$ \\
\hline $\log \left(\mathrm{SEF} \_\mathrm{FW}_{i}\right)$ & $0.44^{* *}(0.05)$ & $0.48^{* *}(0.18)$ & $2.12^{* *}(0.26)$ & $0.06(0.04)$ & $-0.20(0.12)$ & 0.540 .43 \\
\hline Adjusted $R^{2}$ & 0.217 & & & 0.068 & & \\
\hline Pseudo $R^{2}$ & & & 0.103 & & & 0.071 \\
\hline $\begin{array}{l}\text { Hausman test statistic for } \\
\log \left(\mathrm{SEF}_{-} \mathrm{FW}_{i}\right)\end{array}$ & & 0.05 & & & 5.76 & \\
\hline Number of observations & 5168 & 5168 & 5168 & 5168 & 5168 & 5168 \\
\hline Share of positive observations & 0.23 & 0.23 & 0.23 & 0.09 & 0.09 & 0.09 \\
\hline
\end{tabular}

Standard errors in parenthesis. All regressions include sector dummies and dummies for geographical areas of country. All variables and SLARGECO $i$ and SGREEN S $_{i}$ used as instruments for $\log \left(\mathrm{SEF}_{-} \mathrm{FW}_{i}\right)$ in GMM: Hausman test statistic computed as the square of the difference between the OLS and GMM estimates, divided by the difference between their variances.

* Significant at 5\% level.

** Significant at $1 \%$ level. 
estimated. This is an interesting result for it suggests that SEFs are likely to have encouraged entry of firms from developing country into new chemical markets by providing access to chemical technologies. This result is consistent with other findings that the presence of SEFs lowers entry barriers and makes markets more competitive (e.g., Lieberman, 1987). Further, that SEFs do not have a similar impact on MNE investment suggests that first world SEFs are a sources of increased competition for the very same first world companies that gave rise to these SEFs in earlier periods.

\section{Conclusions}

Technological spillovers play an important role in the process of economic growth (see Griliches, 1979; Jaffe, 1986, or Coe and Helpman, 1995). However, the typical description of the mechanism of these spillovers is, in Alfred Marshall's often used phrase, one where "the secrets ... are in the air". Important as this ethereal mechanism may be, there are other mechanisms, more material and more amenable to economic analysis, through which technology is transferred across sectors and countries. What may sometimes appear as spillovers may be the working of an upstream sector of specialized technology suppliers. Though market mediated, the technology flow has real benefits for recipients, and is likely a mechanism through which early users benefit latecomers, lead sectors benefit sectors that arise later, and leaders benefit follower countries.

The economics of this mechanism is very simple. As Romer (1990) has emphasized, the development of technological capability is a fixed cost activity, while the productive application of the technological capability is a (low) marginal cost activity. In our story, firms in the upstream sector invest in developing technology and plant design. If the upstream sector is competitive, then existing downstream firms ultimately pay for these investment costs. Once incurred the costs are sunk. However, the expertise and the technologies developed are process - and not location-specific, and thus, can subsequently be made available to downstream firms in other countries. Moreover, competition between suppliers implies that the expertise and technology will be made available to prices close to marginal cost of transfer.

Our empirical results are consistent with the notion that the greater the number of technology suppliers, the more attractive the terms on which technology is supplied and, all else held constant, the more likely buyers are to invest. We do not mean to suggest that the observed rates of investment in chemical plants in developing countries are being fueled solely by specialist process technology suppliers from the first world and could not be achieved without them. Rather, we interpret our results as suggesting that that the investment is taking place earlier and more rapidly than if developing countries had to rely solely upon chemical producers in the first world to transfer the technology, or even worse, if they had to 're-invent the wheel'-i.e., develop process technologies and the broader engineering expertise required to design and construct chemical plants domestically. In short, the vertical organization of industry in the first world 'matters' not just for the growth of the first world but also for the growth of other nations. 


\section{Acknowledgements}

We thank the TEG Program at CEPR, Stanford University, for its hospitality during the early stages of the preparation of this paper. We are grateful to Dan Black, Shane Greenstein, Zvi Griliches, Pat Hiron, Adam Jaffe, Sam Kortum, Ralph Landau, Jim Markusen, Nathan Rosenberg, Manuel Trajtenberg, Bill Vogt and participants at the applied economics seminars at the University of Pittsburgh, CMU, NBER (Boston), ASSET97 (Marseille), Universidad Carlos III de Madrid, Universitat Pompeu Fabra, University of Leuven and University of Urbino for helpful comments. Zhang Jianyu provided competent research assistance. Fosfuri and Gambardella also thank the Italian Ministry of University and Scientific Research (MURST), and CNR (Committees 10 and 11) for financial support. Financial support from the European Union, DG XII, TSER Project N.SOE1-CT97-1059, is also gratefully acknowledged. The customary disclaimers apply.

\section{Appendix A. Description of the data}

\section{A.1. Plant data}

Our main source of plant level data is Chemical Age Project File (Chemical Age Project File (CAPF), 1989), a data base compiled by Pergamon, London. CAPF provides information on 20,581 plants announced or constructed all over the world in the broadly defined chemical sector during 1980-1989. The database is organized by plants. It reports the name of the company that ordered the plant, the name of the engineering company for that plant (or 'staff' for in-house engineering), the location of the plant (city and country), the name of the chemical process or of the product being produced, the date in which the investment was first reported in the specialized trade press, along with other information. For about $40 \%$ of the plants, CAPF also reports the total cost of investment in the plant in US million dollars. Finally, the database reports the status of the plant along with the date in which the information was last updated. In most of the cases the information was updated in 1988-1989, which suggests that we can reasonably assume that this was the status of the plant at the end of our sample period. There are 14,893 plants in the database that are either 'completed' or 'under construction'. The others are 'planned', 'under study', 'abandoned', 'canceled', 'delayed', or others.

We focused our analysis on the plants that were either completed or under construction. Thus, $\mathrm{SIZE}_{i j}, \mathrm{BUY}_{i j}, \mathrm{MAKE}_{i j}, \mathrm{DOM}_{i j}, \mathrm{MNE}_{i j}$, and SIZE_FW ${ }_{i}$ were obtained by using only the 14,893 plants that are completed or constructed. In counting SEF_FW we used information from all the 20,581 plants in the database. This is because even plants that were planned, under study, abandoned, or other, provided useful information about whether a given SEF was a potential supplier for that technology. For similar reason, we used all the available information about plant costs to compute COST_FW ${ }_{i}$ and the average plant investment cost in LDCs to compute the dollar values of the variables mentioned above. The vast majority of the firms counted in SEF_FW ${ }_{i}$ are independent SEFs, or they engineering subsidiaries of larger chemical groups (especially 
for the European and Japanese companies). Since these normally act as independent companies on the open market, they can also be considered as full-fledged SEFs. There are a few chemical firms that provide engineering services to other (non-affiliated) chemical companies. We also included them as potential suppliers of engineering services for that process.

\section{A.2. Chemical processes}

CAPF plants cover 2081 different chemical processes. However, we focused our analysis on the 136 largest processes with 20 or more plants in the database. Gathering information for all processes for our measures of technological novelty and complexity, is very difficult, and often, prohibitively so. In fact, our sample is a comprehensive set of all the important and widely diffused chemical technologies in the world. It covers 10,012 plants that are completed or in construction, i.e., almost $70 \%$ of all the 14,893 plants completed or in construction in the data base. In addition, in an earlier working paper we report qualitatively similar empirical results using a larger sample of processes, albeit without the extensive controls that we use here (Arora et al., 1996). We also performed similar analyses using a cross-section of all the 2081 processes and aggregate variables for the LDCs as a whole. Again, the qualitative results did not change.

\section{A.3. Sectors}

CAPF classifies its plants in the following 21 sectors (in parenthesis the number of plants that are completed or under construction in each sector): Agricultural Chemicals (116), Air Separation (596), Coal Refining (32), Desalination (40), Engineering Materials (110), Environmental Technologies (75), Fertilizers (1000), Food Products (308), Gas Handling (1014), Inorganic Chemicals (1249), Industrial Gases (613), Minerals and Metallurgy (532), Miscellaneous (505), Organic Chemicals (1114), Oil Refining (2246), Petrochemicals (2155), Pharmaceuticals (745), Plastics and Rubber (1474), Pulp and Paper (396), Synthetic Fuels (135), Textiles and Fibers (438). The sector dummies that we actually used in all our regressions were obtained, however, after aggregating these 21 sectors in nine classes of relatively homogeneous sectors. The nine aggregate sectors are OIL REFINING, PETROCHEMICALS, MINERALS and METALLURGY, PLASTICS and RUBBER, INORGANIC CHEMICALS, AGRICULTURE (Agricultural Chemicals and Fertilizers), GAS (Gas Handling, Air Separation, and Industrial Gases), ORGANIC CHEMICALS (Organic Chemicals, Explosives, Textile and Fibers, Food Products, and Pharmaceuticals), and MISCELLANEOUS (all the rest).

\section{A.4. Nationality of companies and subsidiaries}

We used Predicast's (1991) and other company thesauruses to group all the companies that were subsidiaries of other companies in the data base under the names of their mothers companies, and assign nationalities to companies. We treated the SEFs that were subsidiaries of larger chemical groups as independent firms. However, when an 
SEFs provided services for its parent company, this was counted as a 'make'. We do not find any SEFs from LDCs operating in the first world.

\section{A.5. Limitation of the data base}

CAPF is a commercial data base, and is constructed from various sources such as questionnaires and reports in the trade press. Its vast coverage suggests that biases are unlikely. Its most serious limitation is that for about $17 \%$ of the plants in our sample the name of the engineering company is not given. Conversations with data providers in the industry suggested that these blanks could arise for a number of reasons. Companies may still be looking for suitable engineers (including possibly doing the engineering in-house), or they do not want to disclose the name, or the information is simply missing. However, we also used information about these plants from another database (Hydrocarbon Processing Unit-HPI, compiled by Gulf Publishing, TX) to see whether we could classify the blanks as 'buys' or 'makes'. The details of this diagnostic check are available from the authors upon request. The check was inconclusive because a large number of the identified plants in the other database were still blanks. However, since most of the identified plants that did report the name of an engineering company in the other data base were 'buys', our check ruled out the possibility that the blanks are predominately 'makes'.

We performed all our empirical analyses under different assumptions about the blanks - i.e., all the blanks are 'buys', all the blanks are 'makes', the blanks are 50\% 'buys' and 50\% 'makes', the blanks are distributed between 'buys' and 'makes' in the same proportion as in the case in which the name of the engineering company (or 'staff') is observed. The results presented here are those where we assume that all the blanks are 'buys'. It turns out that all other assumptions about the blanks had even more favorable results for our theory.

\section{A.6. Construction of PROCPAT}

PROCPAT $_{i}$ was constructed as follows. We selected all relevant patents using a keyword search with the process as the keyword. From these, we selected and read the full abstracts of patents that exactly fit our criterion. The patent classes (and sub-classes) into which these patents were classified were examined to ensure that the invention was in fact a process invention. These subclasses of the US patent classification system were used along with the process name as the basis for Boolean queries of the US patent database to generate the final set of patents, one set for each process. (The details of the Boolean queries are available upon request.) The titles (and some abstracts selected at random) of the patents in the final sample for each process were examined to ensure that the final sample did not contain irrelevant patents.

\section{A.7. Countries}

In all our analyses, and for all the variables that we constructed, we defined first world to be all the OECD countries except Mexico, the Czech Republic, Hungary, 
Poland, South Korea and Turkey. These countries joined the OECD only very recently and for our purposes, it was more appropriate to include them in the LDC category. Therefore, our first world countries are all the Western European countries, the USA and Canada, Japan, Australia and New Zealand. The 38 countries in our sample are: Algeria, Argentina, Bangladesh, Brazil, Burma, Chile, China, Colombia, Ecuador, Egypt, Hong Kong, Hungary, India, Indonesia, Iran, Iraq, Kuwait, Malaysia, Mexico, Morocco, Nigeria, Pakistan, Peru, Philippines, Poland, Saudi Arabia, Singapore, South Africa, South Korea, Sri Lanka, Sudan, Syria, Taiwan, Thailand, Tunisia, Turkey, Venezuela, Yugoslavia.

\section{References}

Amemiya, T., 1985. Advanced Econometrics. Harvard Univ. Press, Cambridge MA.

Arora, A., Gambardella, A., 1998. Evolution of industry structure in the chemical industry. In: Arora, A., Landau, R., Rosenberg, N. (Eds.), Chemicals and Long-Term Economic Growth. Wiley, New York.

Arora, A., Fosfuri, A., Gambardella, A. 1996. Division of Labor and the Transmission of Growth. CEPR Working Paper \#474. Stanford University. July.

Arora, A., Landau, R., Rosenberg, N., 1998. Chemicals and Long-Term Economic Growth. Wiley, New York. Arrow, K.J., 1962. Comments on case studies. In: Nelson, R.R. (Ed.), The Rate and the Direction of Inventive Activity: Economic and Social Factors. Princeton Univ. Press, Princeton, NJ.

Barro, R., Lee, J.H. 1994. Data Set for a Panel of 138 Countries. ftp://www.nber.org/pub/barro.lee.

Bresnahan, T., Reiss, P., 1991. Entry and competition in concentrated markets. Journal of Political Economy 99 (5), 977-1009.

Bresnahan, T., Trajtenberg, M., 1995. General-purpose technologies-engines of growth? Journal of Econometrics 65 (1), 83-108.

Chemical Age Project File (CAPF). 1989, Pergamon Financial Data Services, London.

Coe, D.T., Helpman, E., 1995. International R\&D spillovers. European Economic Review 39, 859-887.

Cohen, W., Levinthal, D., 1989. Innovation and learning: the two faces of R\&D. Economic Journal 99, 569-596.

Eaton, J., Kortum, S., 1996. Trade in ideas: patenting and productivity in the OECD. Journal of International Economics 40, 251-278.

Freeman, C., 1968. Chemical process plant: innovation and the world market. National Institute Economic Review 45, 29-51.

Griliches, Z., 1979. Issues in assessing the contribution of research and development to productivity growth. Bell Journal of Economics 10 (1), 92-116.

Hausman, J., 1978. Specification tests in econometrics. Econometrica 46, 1251-1272.

Helpman, E., Trajtenberg, M. 1996. Diffusion of General-Purpose Technologies. NBER Working Paper \#5773. September.

Jaffe, A., 1986. Technological opportunity and spillovers of R\&D: evidence from firms' patents, profits and market value. American Economic Review 76 (5), 984-1001.

Lieberman, M., 1987. Patents, learning by doing, and market structure in the chemical processing industries. International Journal of Industrial Organization 5, 257-276.

Nadiri, M.I. 1993. Innovation and Technological Spillovers. NBER Working Paper \#4423. August.

Predicast's Company Thesaurus. 1991, World Headquarters, Cleveland, OH, Annual Edition.

Rivera-Batiz, L., Romer, P., 1991. Economic integration and endogenous growth. Quarterly Journal of Economics 106, 531-555.

Rodriguez-Clare, A., 1996. Multinationals, linkages, and economic development. American Economic Review 86 (4), 851-873.

Romer, P., 1990. Endogenous technological change. Journal of Political Economy 98 (5), S71-S102. 
Romer, P., 1996. Why, indeed, in America? theory, history, and the origins of modern economic growth. American Economic Review 86 (2), 202-206.

Smith, A., 1776. The Wealth of Nations. 1983 edn. Penguin Books, Harmondsworth, UK.

Stigler, G., 1951. The division of labor is limited by the extent of the market. Journal of Political Economy 59 (3), 185-193.

Teece, D.J., 1977. Technology transfer by multinational firms: the resource cost of transferring technological know-how. The Economic Journal 87, 242-261.

Vernon, R., 1979. The product cycle hypothesis in a new international environment. Oxford Bulletin of Economics and Statistics 41 (4), 255-267.

UN Statistical Yearbook, United Nations, New York, 38th and 39th issues.

World Atlas. 1990, Istituto Geografico De Agostini, Novara, Italy.

Young, A., 1929. Increasing returns and economic progress. Economic Journal, 38, 539, December.

Zucker, L., Darby, M., Armstrong, J., 1998. Geographically localized knowledge: spillovers or markets? Economic Inquiry 36, 65-86. 